\title{
Veillonella denticariosi sp. nov., isolated from human carious dentine
}

\author{
Roy Byun, ${ }^{1}$ Jean-Philippe Carlier, ${ }^{2}$ Nicholas A. Jacques, ${ }^{1}$ \\ Helene Marchandin ${ }^{3}$ and Neil Hunter ${ }^{1}$
}

\author{
Correspondence \\ Roy Byun \\ roy_byun@wmi.usyd.edu.au
}

\author{
${ }^{1}$ Institute of Dental Research, Westmead Centre for Oral Health and Westmead Millennium \\ Institute, Westmead Hospital, Wentworthville, NSW 2145, Australia \\ ${ }^{2}$ Centre National de Référence des Bactéries Anaérobies et du Botulisme, Institut Pasteur, \\ 25 rue du Dr Roux, 75724 Paris Cedex 15, France \\ ${ }^{3}$ Centre Hospitalier Universitaire de Montpellier et EA 3755, Laboratoire de Bactériologie, Hôpital \\ Arnaud de Villeneuve, 371 avenue du Doyen Gaston Giraud, 34295 Montpellier Cedex 5, France
}

\begin{abstract}
Selective culture of human carious dentine for Veillonella strains resulted in the isolation of two strains of a Gram-negative, coccus-shaped bacterium that has not been described previously. Comparative 16S rRNA and dnaK gene sequence analysis indicated that the two strains were homogeneous and comprised a distinct lineage within the genus Veillonella, phylogenetically most closely related to Veillonella rodentium. This was supported by DNA-DNA hybridization, which showed clearly that the two strains were similar and distinct from other Veillonella species, and the production of major cellular fatty acids $\left(C_{13: 0}\right.$ and $\left.C_{17: 1} \omega 8\right)$, which is consistent with other members of the genus Veillonella. Based on these observations, strains RBV81 and RBV $106^{\top}$ represent a novel species, for which the name Veillonella denticariosi sp. nov. is

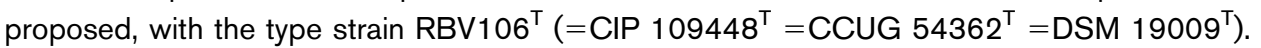

The genus Veillonella comprises small, Gram-negative, non-fermentative, anaerobic cocci that are commonly isolated from the oral cavities and gastrointestinal tracts of humans and animals (Rogosa, 1964). Presently, the genus Veillonella belongs to the family 'Acidaminococcaceae' of the phylum Firmicutes, and is represented by eight species, Veillonella parvula, V. dispar, V. atypica, V. caviae, V. rodentium, V. ratti, V. criceti (Mays et al., 1982; Rogosa, 1965), V. montpellierensis (Jumas-Bilak et al., 2004) and the recently identified ' $V$. rogosae' (Arif et al., 2008). Of these, only $V$. parvula, $V$. dispar, V. atypica, $V$. montpellierensis and ' $V$. rogosae' have been isolated from humans, and they are seldom associated with disease.

With the exception of $V$. criceti, Veillonella species are unable to ferment carbohydrates or amino acids and rely on the fermentation of lactate, pyruvate, malate, fumarate and/or oxaloacetate as a source of carbon and energy (Foubert \& Douglas, 1948; Rogosa, 1984). Veillonella species are frequently isolated from the oral cavity and,

The GenBank/EMBL/DDBJ accession numbers for the 16S rRNA and dnaK gene sequences of strains RBV $106^{\top}$ and RBV81 are EF185167 and EF185168 (16S rRNA genes) and EF219278 and EF219279 $($ dnaK), respectively.

A matrix of DNA-DNA hybridization results and 16S rRNA gene sequence similarities is available as supplementary material with the online version of this paper. in the polymicrobial community of dental plaque, are commonly associated with bacteria that are capable of fermenting carbohydrates to lactic acid, such as strains of Actinomyces, Streptococcus and Lactobacillus. It is believed that veillonellae play an important role in modulating the acid flux (Hoshino et al., 1981), where the metabolic conversion of lactate into the weaker acetic and propionic acids ( $\mathrm{Ng}$ \& Hamilton, 1971) is considered to be anticariogenic, as the weaker acids are less capable of decalcifying enamel (Mikx et al., 1972; van der Hoeven et al., 1978). Likewise, in the anaerobic environment of deep dentinal caries, the conversion of a lactate-dominant to a less acidic environment would favour the growth and proliferation of various anaerobic bacterial species that are commonly found in the deeper regions of carious dentine (Chhour et al., 2005; Edwardsson, 1974; Hoshino, 1985). In this study, we describe the isolation and characterization of two strains of a novel species of Veillonella isolated from human carious dentine.

The bacterial isolates RBV81 and RBV106 ${ }^{\mathrm{T}}$ were selectively isolated from carious lesions of two independently extracted teeth of patients serviced at the Westmead Centre for Oral Health (Sydney, Australia) in 2005. Carious dentine was extracted as described previously (Martin et al., 2002) and plated on Veillonella agar (Rogosa, 1956; Rogosa et al., 1958) supplemented with vancomycin (final concentration $7.5 \mu \mathrm{g} \mathrm{ml}^{-1}$ ). Plates were 
incubated at $37{ }^{\circ} \mathrm{C}$ in an anaerobic atmosphere $\left(90 \% \mathrm{~N}_{2}\right.$, $5 \% \mathrm{H}_{2}, 5 \% \mathrm{CO}_{2}$ by vol.) for $48 \mathrm{~h}$ in an anaerobic workstation (Don Whitley Scientific). Isolates were presumptively identified by PCR-RFLP analysis of $16 \mathrm{~S}$ rRNA genes (Sato et al., 1997). Strains RBV81 and RBV106 ${ }^{\mathrm{T}}$ were identified as having an identical restriction profile to that of $V$. rodentium ATCC $17743^{\mathrm{T}}$.

Colonies of strains $\mathrm{RBV} 106^{\mathrm{T}}$ and RBV81 cultured on Veillonella agar in an anaerobic atmosphere for $48 \mathrm{~h}$ at $37{ }^{\circ} \mathrm{C}$ were circular, smooth, beige coloured, opaque, convex and approximately $2 \mathrm{~mm}$ in diameter. Both strains had Gram-negative, coccus-shaped cells arranged singularly or in pairs. Cells were non-spore-forming and non-motile.

For negative staining, bacteria were grown in Veillonella broth at $37{ }^{\circ} \mathrm{C}$ in an anaerobic atmosphere for $48 \mathrm{~h}$. A drop of the bacterial suspension was held on a 200-mesh copper grid with a carbon-coated pioloform/Formvar support film for $1 \mathrm{~min}$ and removed. The grids were then negatively stained with phosphotungstic acid for $30 \mathrm{~s}$ and removed. After allowing the grids to dry for $30 \mathrm{~min}$, they were observed under a Philips CM10 electron microscope. The cells were spherical in shape with a convoluted surface and varied in size from 0.3 to $0.5 \mu \mathrm{m}$, with a mean size of $0.4 \mu \mathrm{m}$. This is consistent with previous observations of other members of the genus Veillonella (Bladen \& Mergenhagen, 1964; Jumas-Bilak et al., 2004).

For electron microscopy of ultrathin sections, cells were fixed in Karnovsky's fixative for $1 \mathrm{~h}$. The bacteria were then washed in phosphate buffer and dehydrated using graded ethanol and embedded in fresh Spurr's resin. Ultrathin sections were cut using a Reichert Ultracut E microtome and picked up on 400-mesh copper grids. The sections were stained with uranyl acetate and lead citrate and observed under a Philips CM10 electron microscope at high magnification to distinguish cellular structures (Fig. 1). The ultrathin sections allowed visualization of structural components (outer membrane, thin peptidoglycan layer and cytoplasmic membrane) that are characteristic of a Gram-negative cell wall and consistent with previous reports for other members of the genus Veillonella (Bladen \& Mergenhagen, 1964; Jumas-Bilak et al., 2004).

Conventional biochemical analysis for anaerobic organisms and subsequent determination of metabolic end products were performed as described previously (Carlier, 1985; Holdeman et al., 1977). For the Rapid ID 32A system (bioMérieux), cells were grown for $24 \mathrm{~h}$ on Veillonella agar at $37{ }^{\circ} \mathrm{C}$ in an anaerobic atmosphere and then collected and resuspended in sterile distilled water and analysis was performed according to the manufacturer's instructions. Cellular fatty acid composition was analysed by GC according to Veys et al. (1989). Briefly, strains were grown anaerobically in $10 \mathrm{ml}$ trypticase-glucose-yeast extract (TGY) medium at $37{ }^{\circ} \mathrm{C}$ for $48 \mathrm{~h}$ in an anaerobic jar containing $5 \% \mathrm{H}_{2}, 5 \% \mathrm{CO}_{2}$ and $90 \% \mathrm{~N}_{2}$ (by vol.). Methyl esters were chromatographed on a fused-silica capillary

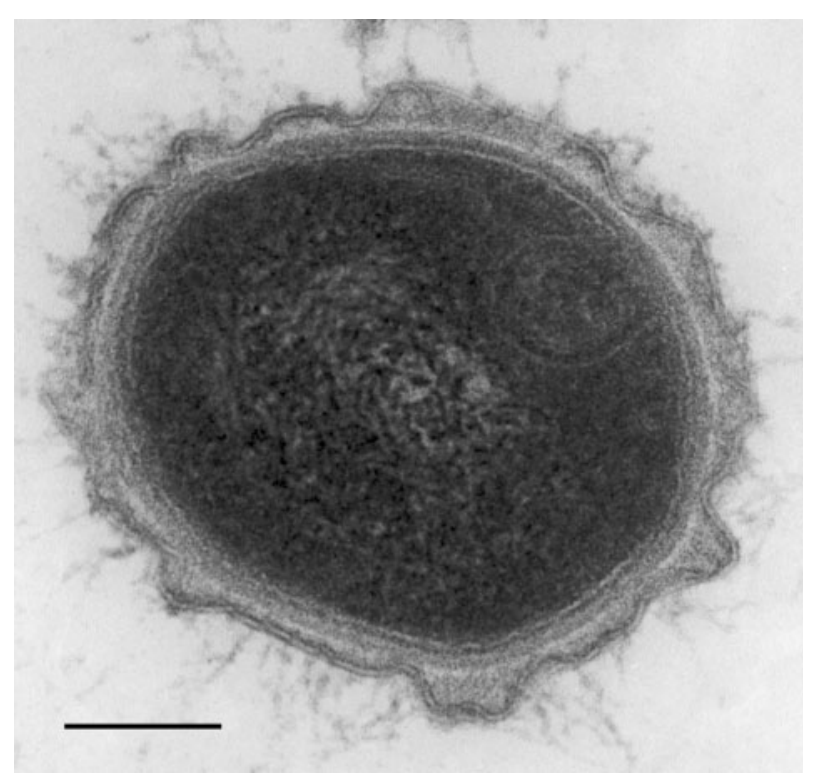

Fig. 1. Electron micrograph of an ultrathin section of a cell of strain RBV $106^{\top}$. Bar, $100 \mathrm{~nm}$.

column $(25 \mathrm{~m} \times 0.25 \mathrm{~mm}$ i.d. $)$ coated with $5 \%$ methyl phenyl silicone (film thickness $0.25 \mu \mathrm{m}$ ).

Strains RBV81 and RBV106 ${ }^{\mathrm{T}}$ were strictly anaerobic, catalase-negative, indole-negative and reduced nitrate to nitrite. The strains were resistant to vancomycin $(5 \mu \mathrm{g})$ but susceptible to kanamycin $(1 \mathrm{mg})$, colistin $(10 \mu \mathrm{g})$, metronidazole $(4 \mu \mathrm{g})$ and bile identification discs, which is characteristic of other Veillonella species, except $V$. montpellierensis and V. ratti (Jumas-Bilak et al., 2004). Interestingly, gas was not produced in TGY deep agar, which is atypical for the genus Veillonella. Biochemical analysis showed that neither strain was able to ferment carbohydrates (glucose, fructose, lactose, maltose, mannose and sucrose) but could metabolize lactate to acetate and propionate $(5.5$ and $5.4 \mathrm{mM}$, respectively, for strain RBV $106^{\mathrm{T}}$; 5.8 and $6.4 \mathrm{mM}$, respectively, for strain RBV81). This was supported by the use of the Rapid ID 32A system, which showed that both strains were only positive for the reduction of nitrates (NIT) and for the hydrolysis of arginine (ARG). Cellular fatty acid profiles for RBV81 and RBV106 ${ }^{\mathrm{T}}$ were similar to each other and consistent with those of other Veillonella species (Table 1), with the dominant fatty acids $\mathrm{C}_{13: 0}$ and $\mathrm{C}_{17: 1} \omega 8$ being synthesized (Jumas-Bilak et al., 2004). Minor fatty acids included $\mathrm{C}_{12: 0}$, iso- $\mathrm{C}_{14: 0}, \mathrm{C}_{14: 0}$, anteiso- $\mathrm{C}_{15: 0}, \mathrm{C}_{15: 0}$, $\mathrm{C}_{16: 1} \omega 9 \mathcal{c}, \mathrm{C}_{16: 0}, \mathrm{C}_{18: 1} \omega 9 c$ and $\mathrm{C}_{18: 0}$. Fatty acids $\mathrm{C}_{11: 0}$, iso- $\mathrm{C}_{16: 0}, \mathrm{C}_{17: 0} \Delta, \mathrm{C}_{17: 0}, \mathrm{C}_{16: 0} 2-\mathrm{OH}, \mathrm{C}_{18: 1} \omega 9 t$ and $\mathrm{C}_{20: 0}$ were found in trace amounts. Strains RBV81 and RBV106 were found to differ from other Veillonella species in the production of significant amounts of iso- $\mathrm{C}_{14: 0}$ as well as three unknown compounds. 
Table 1. Relative content of cellular fatty acids of strains $R B V 106^{\top}$ and $R B V 81$ and other Veillonella species

Reference strains (data from Jumas-Bilak et al., 2004): 1, V. atypica ATCC $17744^{\mathrm{T}} ; 2$, V. caviae DSM $20738^{\mathrm{T}} ; 3$, V. criceti DSM $20734^{\mathrm{T}} ; 4$, V. dispar ATCC $17748^{\mathrm{T}} ; 5$, V. ratti ATCC $17746^{\mathrm{T}} ; 6$, V. rodentium ATCC $17743^{\mathrm{T}} ; 7$, V. parvula ATCC $17745 ; 8$, V. montpellierensis CIP $107992^{\mathrm{T}}$. Data are percentages of total cellular fatty acids. For unsaturated fatty acids, the position of the double bond can be located by counting from the methyl $(\omega)$ end of the carbon chain; cis and trans isomers are respectively indicated by the suffixes $c$ and $t$. Cyclopropane acid are identified by $\Delta$. On the basis of their retention times, unknown compounds 2 and 3 may correspond to anteiso- $\mathrm{C}_{16: 0}$ and $\mathrm{C}_{16: 1} \omega 7 c$, respectively. -, Not detected; NA, no data available (these components were not reported by Jumas-Bilak et al., 2004).

\begin{tabular}{|c|c|c|c|c|c|c|c|c|c|c|}
\hline Fatty acid & $\mathrm{RBV} 106^{\mathrm{T}}$ & RBV81 & 1 & 2 & 3 & 4 & 5 & 6 & 7 & 8 \\
\hline $\mathrm{C}_{11: 0}$ & 0.5 & 0.7 & 1.1 & 1.4 & 2 & 0.8 & 2.1 & 1.6 & 1.8 & 2.3 \\
\hline $\mathrm{C}_{12: 0}$ & 3.0 & 4.5 & 3.8 & 4 & 1.4 & 3.8 & 4.5 & 5 & 4.9 & 7 \\
\hline $\mathrm{C}_{13: 0}$ & 12.9 & 19.2 & 20.4 & 7.3 & 16.3 & 23.5 & 20 & 25.3 & 24 & 6.3 \\
\hline iso- $\mathrm{C}_{14: 0}$ & 5.1 & 5.8 & 0.6 & 1.2 & - & 1.5 & 0 & - & 1.9 & - \\
\hline $\mathrm{C}_{14: 0}$ & 3.9 & 5.2 & 5.7 & 3.1 & 1.2 & 4.9 & 2 & 9.2 & 6.5 & 5 \\
\hline anteiso- $\mathrm{C}_{15: 0}$ & 2.4 & 4.1 & - & - & - & - & - & - & - & - \\
\hline $\mathrm{C}_{15: 0}$ & 4.4 & 6.3 & 17.7 & 7 & 12.7 & 7 & 10.3 & 11.6 & 12 & 6.3 \\
\hline $\mathrm{C}_{14: 0} 2-\mathrm{OH}$ & - & - & 0.3 & - & 0.3 & - & 1 & - & - & - \\
\hline iso- $\mathrm{C}_{16: 0}$ & 3.2 & 0.8 & - & - & - & - & - & - & - & - \\
\hline Unknown 1 & 4.2 & 3.6 & - & - & - & - & - & - & - & - \\
\hline Unknown 2 & 5.1 & 5.4 & - & - & - & - & - & - & - & - \\
\hline $\mathrm{C}_{16: 1} \omega 9 c$ & 4.5 & 5.5 & 5.2 & 10.6 & 4.2 & 7.7 & 4.8 & 5.5 & 5.2 & 8.4 \\
\hline Unknown 3 & 4.2 & 1.3 & - & - & - & - & - & - & - & - \\
\hline $\mathrm{C}_{16: 0}$ & 8.6 & 6.0 & 7.5 & 10.3 & 3.7 & 8.4 & 4.6 & 6.7 & 7 & 12.9 \\
\hline $\mathrm{C}_{17: 1} \omega 8$ & 10.1 & 13.1 & 25.7 & 29.9 & 48.9 & 25.6 & 36.9 & 17 & 22.3 & 20.7 \\
\hline $\mathrm{C}_{17: 0} \Delta$ & 3.7 & 1.4 & - & - & - & - & - & - & - & - \\
\hline $\mathrm{C}_{17: 0}$ & 3.2 & 2.3 & 2.4 & 2.5 & 2.6 & 2.5 & 2.4 & 4.2 & 4.1 & 2 \\
\hline $\mathrm{C}_{16: 0} 2-\mathrm{OH}$ & 2.3 & 0.7 & - & - & - & - & - & - & - & - \\
\hline $\mathrm{C}_{18: 1} \omega 9 c$ & 5.7 & 6.8 & 4.3 & 14.3 & 2.8 & 8 & 6.1 & 6.7 & 6.2 & 17.4 \\
\hline $\mathrm{C}_{18: 1} \omega 9 t$ & 3.5 & 2.8 & - & 1.9 & 1.2 & - & - & - & - & 2 \\
\hline $\mathrm{C}_{18: 0}$ & 6.6 & 3.5 & 2.7 & 6.2 & 2.1 & 5.7 & 5.8 & 6.7 & 3.9 & 11.1 \\
\hline $\mathrm{C}_{19: 0} \Delta$ & - & 0.5 & NA & NA & NA & NA & $\mathrm{NA}$ & NA & NA & NA \\
\hline $\mathrm{C}_{20: 0}$ & 2.6 & 1.6 & NA & $\mathrm{NA}$ & $\mathrm{NA}$ & $\mathrm{NA}$ & $\mathrm{NA}$ & $\mathrm{NA}$ & NA & NA \\
\hline
\end{tabular}

DNA was extracted from cells collected from Veillonella agar plates resuspended in $50 \mathrm{mM}$ Tris/ $\mathrm{HCl}(\mathrm{pH}$ 8.0) using the QIAamp DNA Mini kit (Qiagen) as described by the manufacturer. PCR and sequencing of the 16S rRNA and dnaK genes was performed using primers described previously (Marchandin et al., 2003; Paster et al., 2001). Sequences were aligned using the program CLUSTAL_X (version 1.83) and phylogenetic analysis was performed using MEGA (version 3.1). Distance matrices were constructed using Kimura's two-parameter method and phylogenetic trees were constructed by the neighbourjoining method (Figs 2 and 3). Bootstrap analysis was based on 1000 replicates and support is represented as percentages.

A contiguous sequence of $1497 \mathrm{bp}$ of the 16S rRNA gene was obtained from strains RBV106 ${ }^{\mathrm{T}}$ and RBV81, with two and three ambiguous positions, respectively, observed in the chromatograms, which is consistent with the observation of intrachromosomal variation between $16 \mathrm{~S}$ rRNA gene copies in some Veillonella strains (Marchandin et al.,
2003). The 16S rRNA gene sequences of strains RBV106 ${ }^{\mathrm{T}}$ and RBV81 differed at only a single site $(99.9 \%)$ and were phylogenetically most closely related to $V$. rodentium ATCC $17743^{\mathrm{T}}$, with 99.1 and $99.0 \%$ sequence identity, respectively (Supplementary Table S1, available in IJSEM Online).

Because of the high level of sequence conservation in the 16S rRNA gene sequence between several Veillonella species and the relatively high level of intrachromosomal heterogeneity in some Veillonella isolates (Jumas-Bilak et al., 2004; Marchandin et al., 2003), the $70 \mathrm{kDa}$ heat-shock protein gene $(d n a K)$ was also partially sequenced as an alternate genetic marker. Analysis of partial dnaK sequences (640 bp) of strains RBV106 ${ }^{\mathrm{T}}$ and RBV81 showed that they share $99.5 \%$ identity. Consistent with observations in the 16S rRNA gene, both strains were phylogenetically most closely related to $V$. rodentium ATCC $17743^{\mathrm{T}}$ (Fig. 3), with 95.2 and $95.7 \%$ sequence identity, respectively. This is comparable to the level of sequence identity observed between the dnaK sequences of the type 


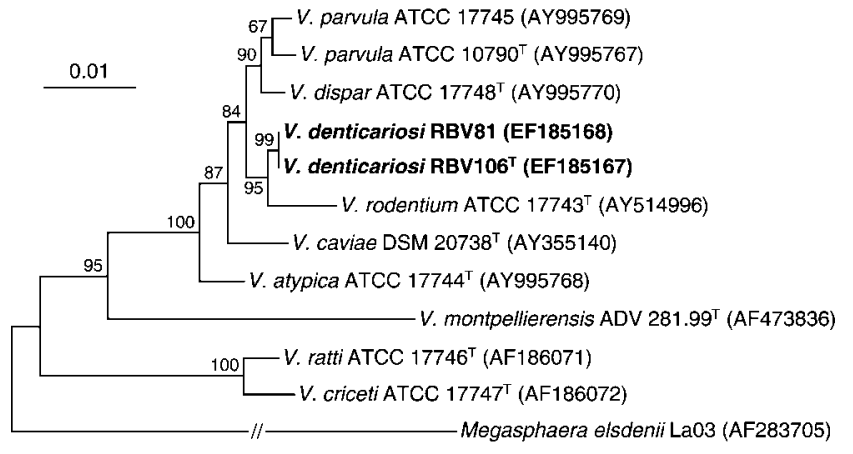

Fig. 2. Neighbour-joining phylogenetic tree based on the $16 \mathrm{~S}$ rRNA sequences (1497 bp) of type strains of Veillonella species. Bootstrap values at nodes are represented as percentages of 1000 replicates. Bar, genetic distance of $1 \%$.

strains of the closely related species $V$. parvula and $V$. dispar (Jumas-Bilak et al., 2004), supporting the claim that strains RBV106 ${ }^{\mathrm{T}}$ and RBV81 represent a novel species. The phylogenetic tree for $d n a K$ is congruent with that of the

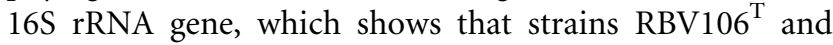
RBV81 are distinct from other Veillonella species and most closely related to $V$. rodentium.

DNA-DNA hybridization to determine genetic relatedness was performed in NucleoLink micro-well strips (Nalge Nunc International) as described previously (Christensen et al., 2000), except that hybridization was performed at $42{ }^{\circ} \mathrm{C}$ for $18 \mathrm{~h}$ with $50 \mathrm{ng}$ photobiotin acetate-labelled DNA per well in $100 \mu \mathrm{l} 2 \times$ SSC buffer, $5 \times$ Denhardt's solution, $3 \%(\mathrm{w} / \mathrm{v})$ dextran sulphate, $50 \%(\mathrm{v} / \mathrm{v})$ formamide and $50 \mu \mathrm{g}$ salmon sperm DNA $\mathrm{ml}^{-1}$ (Sigma). The control wells contained purified genomic DNA from Escherichia coli XL1-Blue. Strains RBV81 and RBV106 showed a high level of DNA relatedness (87\%; Supplementary Table S1) and are most closely related to V. rodentium ATCC $17743^{\mathrm{T}}$ (49 and $48 \%$, respectively).

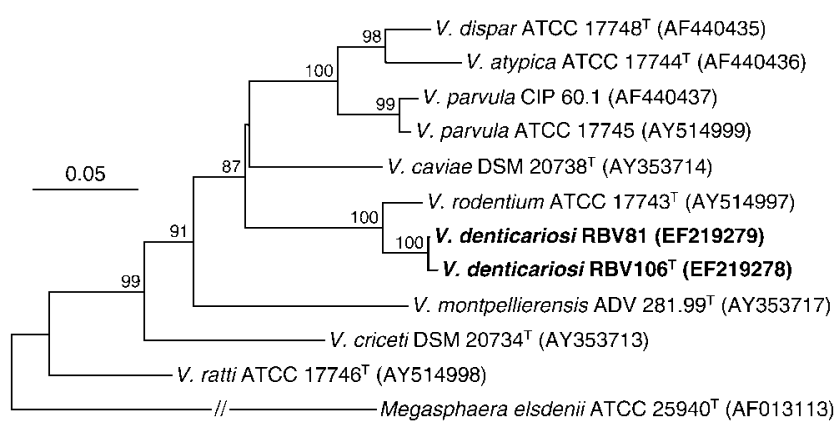

Fig. 3. Neighbour-joining phylogenetic tree based on partial dnaK sequences (640 bp) of type strains of Veillonella species. Bootstrap values at nodes are represented as percentages of 1000 replicates. Bar, genetic distance of $5 \%$.

\section{Description of Veillonella denticariosi sp. nov.}

Veillonella denticariosi (den.ti.ca.ri.o'si. L. n. dens, dentis tooth; L. adj. cariosus rotten, decayed; N.L. gen. n. denticariosi of a decayed tooth).

Cells are non-motile, non-spore-forming cocci, arranged singly or in pairs, with a mean diameter of $0.4 \mu \mathrm{m}$. Irregular masses of cells are also observed in TGY broth. Colonies on Veillonella agar are circular, smooth, beige coloured, opaque and convex and are approximately $2 \mathrm{~mm}$ in diameter after $48 \mathrm{~h}$ at $37^{\circ} \mathrm{C}$ in an anaerobic atmosphere. Cells are strict anaerobes, Gram-negative, with a convoluted surface. Cells are catalase-negative, reduction of nitrates is positive, arginine dihydrolase is present and gas is not produced. Lactate is fermented, with the major metabolic end products being acetate and propionate. Major cellular fatty acids produced are $\mathrm{C}_{13: 0}$ and $\mathrm{C}_{17: 1} \omega 8$, consistent with other Veillonella species, with unique fatty acids iso- $\mathrm{C}_{14: 0}$ and three unknown compounds being produced. Can also be differentiated from other Veillonella species by $16 \mathrm{~S}$ rRNA gene and dnaK sequencing.

The type strain RBV106 ${ }^{\mathrm{T}}\left(=\mathrm{CIP} 109448^{\mathrm{T}}=\right.$ CCUG $54362^{\mathrm{T}}$ $\left.=\mathrm{DSM} 19009^{\mathrm{T}}\right)$ and a reference strain RBV81 $(=\mathrm{CIP}$ $109449=$ CCUG $54361=$ DSM 19010) were isolated from human carious dentine.

\section{Acknowledgements}

We are grateful to Mary Simonian for providing assistance with electron microscopy and Maria Manich for technical assistance. This work was supported by the NIDCR grant R01 DE015272-07.

\section{References}

Arif, N., Do, T., Byun, R., Sheehy, E., Clarke, D., Gilbert, S. C. \& Beighton, D. (2008). Veillonella rogosae sp. nov., an anaerobic, Gramnegative coccus isolated from the dental plaque of caries-free children. Int J Syst Evol Microbiol 58 (in press).

Bladen, H. A. \& Mergenhagen, S. E. (1964). Ultrastructure of Veillonella and morphological correlation of an outer membrane with particles associated with endotoxic activity. J Bacteriol 88, 1482-1492.

Carlier, J.-P. (1985). Gas chromatography of fermentation products: its application in diagnosis of anaerobic bacteria. Bull Inst Pasteur 83, 57-69.

Chhour, K. L., Nadkarni, M. A., Byun, R., Martin, F. E., Jacques, N. A. \& Hunter, N. (2005). Molecular analysis of microbial diversity in advanced caries. J Clin Microbiol 43, 843-849.

Christensen, H., Angen, Ø., Mutters, R., Olsen, J. E. \& Bisgaard, M. (2000). DNA-DNA hybridization determined in micro-wells using covalent attachment of DNA. Int J Syst Evol Microbiol 50, 1095-1102.

Edwardsson, S. (1974). Bacteriological studies on deep areas of carious dentine. Odontol Revy Suppl 32, 1-143.

Foubert, E. L. \& Douglas, H. C. (1948). Studies on the anaerobic micrococci. II. The fermentation of lactate by Micrococcus lactilyticus. J Bacteriol 56, 35-36.

Holdeman, L. V., Cato, E. P. \& Moore, W. E. C. (1977). Anaerobe Laboratory Manual, 4th edn. Blacksburg, VA: Virginia Polytechnic Institute and State University. 
Hoshino, E. (1985). Predominant obligate anaerobes in human carious dentin. J Dent Res 64, 1195-1198.

Hoshino, E., Karino, H. \& Yamada, T. (1981). Lactate metabolism by human dental plaque and Veillonella under aerobic and anaerobic conditions. Arch Oral Biol 26, 17-22.

Jumas-Bilak, E., Carlier, J.-P., Jean-Pierre, H., Teyssier, C., Gay, B., Campos, J. \& Marchandin, H. (2004). Veillonella montpellierensis sp. nov., a novel, anaerobic, Gram-negative coccus isolated from human clinical samples. Int J Syst Evol Microbiol 54, 1311-1316.

Marchandin, H., Teyssier, C., Siméon de Buochberg, M., JeanPierre, H., Carriere, C. \& Jumas-Bilak, E. (2003). Intra-chromosomal heterogeneity between the four $16 \mathrm{~S}$ rRNA gene copies in the genus Veillonella: implications for phylogeny and taxonomy. Microbiology 149, 1493-1501.

Martin, F. E., Nadkarni, M. A., Jacques, N. A. \& Hunter, N. (2002). Quantitative microbiological study of human carious dentine by culture and real-time PCR: association of anaerobes with histopathological changes in chronic pulpitis. J Clin Microbiol 40, 1698-1704.

Mays, T. D., Holdeman, L. V., Moore, W. E. C., Rogosa, M. \& Johnson, J. L. (1982). Taxonomy of the genus Veillonella Prévot. Int J Syst Bacteriol 32, 28-36.

Mikx, F. H., van der Hoeven, J. S., Konig, K. G., Plasschaert, A. J. \& Guggenheim, B. (1972). Establishment of defined microbial ecosystems in germ-free rats. I. The effect of the interactions of Streptococcus mutans or Streptococcus sanguis with Veillonella alcalescens on plaque formation and caries activity. Caries Res 6, 211-223.

Ng, S. K. \& Hamilton, I. R. (1971). Lactate metabolism by Veillonella parvula. J Bacteriol 105, 999-1005.
Paster, B. J., Boches, S. K., Galvin, J. L., Ericson, R. E., Lau, C. N., Levanos, V. A., Sahasrabudhe, A. \& Dewhirst, F. E. (2001). Bacterial diversity in human subgingival plaque. J Bacteriol 183, 3770-3783.

Rogosa, M. (1956). A selective medium for the isolation and enumeration of the Veillonella from the oral cavity. J Bacteriol 72, 533-536.

Rogosa, M. (1964). The genus Veillonella. I. General cultural, ecological, and biochemical considerations. J Bacteriol 87, 162-170.

Rogosa, M. (1965). The genus Veillonella. IV. Serological groupings, and genus and species emendations. J Bacteriol 90, 704-709.

Rogosa, M. (1984). Anaerobic Gram-negative cocci. In Bergey's Manual of Systematic Bacteriology, vol. 1, pp. 680-685. Edited by N. R. Krieg \& J. G. Holt. Baltimore: Williams \& Wilkins.

Rogosa, M., Fitzgerald, R. J., MacKintosh, M. E. \& Beaman, A. J. (1958). Improved medium for selective isolation of Veillonella. J Bacteriol 76, 455-456.

Sato, T., Sato, M., Matsuyama, J. \& Hoshino, E. (1997). PCRrestriction fragment length polymorphism analysis of genes coding for $16 \mathrm{~S}$ rRNA in Veillonella spp. Int J Syst Bacteriol 47, $1268-1270$.

van der Hoeven, J. S., Toorop, A. I. \& Mikx, R. H. (1978). Symbiotic relationship of Veillonella alcalescens and Streptococcus mutans in dental plaque in gnotobiotic rats. Caries Res 12, 142-147.

Veys, A., Callewaert, W., Waelkens, E. \& Van den Abbeele, K. (1989). Application of gas-liquid chromatography to the routine identification of nonfermenting Gram-negative bacteria in clinical specimens. J Clin Microbiol 27, 1538-1542. 